\title{
REPRESENTAÇÔES DO FEMININO EM OS SIMPSONS: TRANSFORMAÇÕES NAS RELAÇÕES DE GÊNERO NOS SÉCULOS XX E XXI
}

\author{
REPRESENTATIONS OF WOMEN IN THE SIMPSONS: CHANGES IN \\ GENDER RELATIONS IN THE XX AND XXI CENTURIES
}

\author{
REPRESENTACIONES DEL FEMENINO EN LOS SIMPSONS: CAMBIOS EN \\ LAS RELACIONES DE GÉNERO EN LOS SIGLOS XX Y XXI
}

\author{
Alessandro de Almeida \\ Dr., IFNM \\ alessandroedales@yahoo.com.br \\ Regina Célia Lima Caleiro \\ Dra., UEMC \\ regina.caleiro@hotmail.com
}

\begin{abstract}
Resumo: Criado em 1987 e propagado nas televisões brasileiras a partir de 1991, o desenho animado Os Simpsons apresenta uma sátira à família e à sociedade americana. Nessa produção audiovisual, o maior destaque é dado a figuras masculinas como Bart e Homer Simpson. De modo paralelo, convém ressaltar o intuito de apresentar alterações de comportamento das mulheres e das relações de gênero nas últimas duas décadas. Sob essa perspectiva, outra peculiaridade vincula-se ao fato de que, geralmente, o desenho versa sobre temáticas da contracultura, em que as personagens vovó Simpson, Marge e Lisa Simpson representam símbolos do feminismo dos anos 1960 e, paradoxalmente, compõem e estabelecem um equilíbrio que mantém a família nuclear simpsoniana. Para o debate sobre essa problemática da hegemonia masculina sobre o feminino, utilizaremos alguns episódios da série e a repercussão destes propagadas pela internet que expõem a relevância da discussão para o entendimento das transformações ocorridas nas relações familiares contemporâneas.
\end{abstract}

Palavras-chave: Simpsons, feminino, desenho animado, mídia.

Abstract: Created in 1987 and broadcasted by Brazilian televisions since 1991, the cartoon The Simpsons lampoons American society and family. In that audiovisual production, the greatest prominence is given to male figures as Bart and Homer Simpson. In a parallel way, it should be emphasized the purpose to show changes of women behavior and gender relations in the last two decades. From this perspective, another peculiarity is linked to the fact that usually the cartoon deals with counterculture themes, in which the characters Grandma Simpson, Marge and Lisa Simpson represent symbols of the 1960's feminism while, paradoxically, reconciling and striking a balance that keeps the nuclear Simpson family. For the debate on the issue of male dominance over females we will allude to some episodes of that sitcom and its resonance on the internet which show the relevance of the discussion to the understanding of the changes in the contemporary family relationships.

Keywords: Simpsons, female, cartoon, media.

Resumen: Creado en 1987 y propagado en televisores brasileños a partir de 1991, la serie animada de televisión Los Simpsons presenta una sátira a la familia y a la sociedad estadounidense. En esta producción audiovisual, el énfasis se da a figuras masculinas como Bart y Homer Simpson. También 
es necesario resaltar la intención de presentar los cambios de comportamiento de las mujeres y relaciones de género en las últimas dos décadas. Desde esa perspectiva, otra particularidad se une al hecho de que, generalmente, el dibujo aborda temas de contracultura, en que los personajes de la abuela Simpson, Marge y Lisa Simpson representan símbolos del femenismo de los años 1960 y, paradójicamente, conforman y establecen un equilibrio que mantiene la familia nuclear simpsoniana. Para el debate sobre esta cuestión de la hegemonía masculina sobre el femenino, utilizaremos algunos episodios de la serie y las repercusiones de estos propagados por internet que exponen la relevancia de la discusión para la comprensión de los cambios en las relaciones familiares contemporáneas.

Palabras-clave: Simpsons, femenino, dibujo animado, medios de comunicación.

\section{Introdução}

O desenho animado teve início em 1987, com curtas de 30 segundos para a série de televisão The Tracey Ulman Show, e foi transformado em um desenho apresentado em aproximadamente 22 minutos, atingindo diversas emissoras pelo mundo. O desenho criado pelo cartunista Matt Groening, teve boa aceitação dos telespectadores e foi iniciado com um especial de Natal de meia hora, em 17 de dezembro de 1989, tornando-se série regular em 14 de janeiro de 1990. Os Simpsons é uma produção da Gracie Films associada com a Twentieth Century Fox Television. Matt Groeing, James Brooks e Al Jean são os produtores executivos e Film Roman faz a animação (AMERENO, 2006, p.49-63). Os episódios cuja produção se estende por aproximadamente seis meses cada um, comumente fazem inúmeras alusões que buscam identificar o telespectador com o desenho por meio da apresentação de personalidades, cenas de filmes, episódios políticos e históricos diversos.

As personagens que compõem Os Simpsons residem em Springfield, uma cidade fictícia, e não há menção do Estado. A série retrata uma família de classe média americana e satiriza os fatos cotidianos, os percalços e as resoluções das questões familiares.

As personagens principais da série são caracterizadas da seguinte forma: Homer Simpson é o chefe de família, trabalha como inspetor de segurança na Usina Nuclear local e tem comportamentos pautados pelo vício, despreocupação e até algumas falhas de caráter.

Marge é uma mulher aparentemente virtuosa, que descende de uma linhagem de esposas e mães de TV (boazinhas e organizadoras da família).

Bart é um garoto de dez anos que despreza qualquer tipo de autoridade e regras, faz maldades e busca levar vantagem em tudo que se propõe a fazer. Convêm ressaltar que o desrespeito (ou descaso), às autoridades e a transgressão às regras passaram a ser uma característica da série que transcende a uma particularidade de Bart Simpson.

Lisa, com oito anos, é inteligente e, em meio a um mundo caótico, persiste em acreditar no racionalismo para a correção dos problemas, luta pelas causas ambientais, é 
feminista e virtuosa, toca saxofone e segue dieta vegetariana. A bebê Maggie, que, apesar de não falar e nem manifestar as emoções e sempre sugando sua chupeta, é frequentemente abandonada pela família, mas consegue tomar atitudes sozinha e de forma inteligente, como acontece com a maior parte das figuras femininas de Os Simpsons.

À família nuclear soma-se um casal de idosos, os pais de Homer, denominados como Vovô e Vovó Simpson.

\section{As mulheres da família Simpson}

Apesar de o desenho ter 21 anos de longevidade na mídia televisiva e eletrônica, a história ficcional de seus personagens remonta aos anos 1960. Principalmente, nos episódios que envolvem a "Vovó Simpson" e sua influência no comportamento de Lisa e Marge em diferentes episódios.

Para elucidar a relação dos Simpsons com o universo cultural e político dos anos de 1960 e 1970, o episódio "Vovó Simpson", da sétima temporada, transmitido pela primeira vez em novembro de 1995, é fundamental. Nele, Homer, após simular sua morte para não ser explorado pelo Sr. Burns, encontra-se cheio de problemas, pois, sem o emprego, as empresas de utilitários não prestariam serviços para Os Simpsons. Procurando o cartório para regularizar sua situação de vivo, ele descobre que sua mãe está viva, mas não acredita. Procurando a sepultura de sua mãe no cemitério, Homer encontra sua própria sepultura e, ao pular para dentro dela, é questionado por sua mãe, estabelecendo o seguinte diálogo:

- Seu homem horrível! (mãe)

_ Saia da cova de meu filho!

_ Lamento desapontá-la, senhora, mas a cova é minha. (Homer)

_ Espere aí.

- Mãe?

_ Homer? (mãe)

Após o encontro com sua mãe, Homer a convida a morar em sua casa. Logo, Lisa Simpson percebe que sua avó é procurada pela polícia. Incomodados com o passado da vovó, os Simpsons a pressionam e ela rememora seu passado de ativista-pacifista. Influenciada pelos pressupostos revolucionários e as premissas de mudanças dos anos de 1960, a vovó Simpson esbarrava no conservadorismo de seu marido, Abe Simpson. Porém, na faculdade, ela dizia encontrar adeptos das ideias da contracultura que a motivavam a lutar. O principal alvo dos 
jovens amigos da vovó Simpson era o "Laboratório de Guerra Biológica" do Sr. Burns. Os jovens, então, lutavam contra “o puro demônio”, ou seja, o Sr. Burns, dizendo:

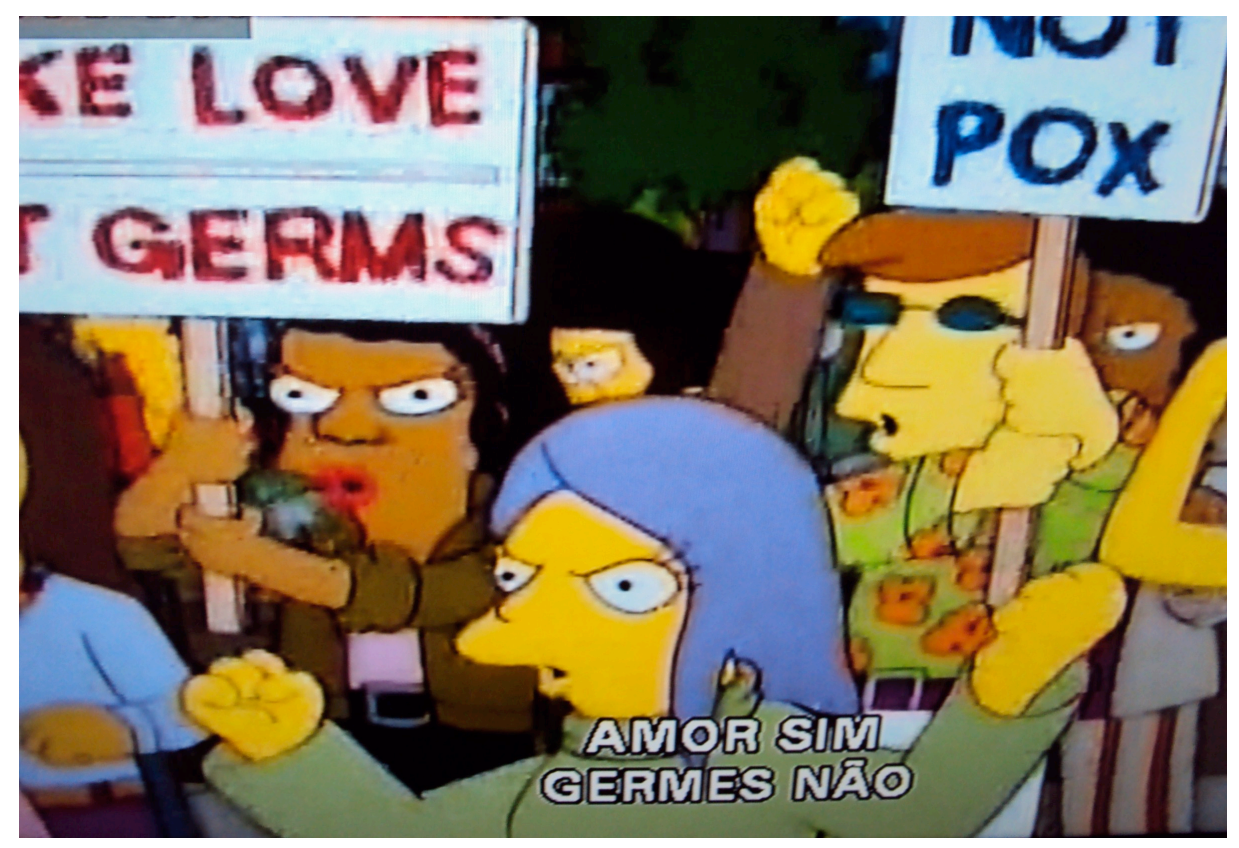

Figura 1: Jovens contra o Laboratório de Guerra Biológica do Sr. Burns Fonte: Episódio "Vovó Simpson” (1995).

Contrapondo-se à imagem positiva de Vovó Simpson as personagens masculinas, Vovô Simpson, Homer e o Sr. Burns, são caracterizados de forma depreciativa. Abe, avô da família Simpson é caracterizado como um conservador que impedia a avó de lutar pelos ideais libertários e feministas dos anos de 1960. Esta condição é parecida com a que Homer impõe a Marge Simpson. É salutar, enfatizar que a vovó Simpson tornou-se refugiada e afastou-se da família defendendo seus ideais. Por outro lado, Marge mantem-se casada com Homer e abdica de seus intuitos e interesses racionalistas em prol da manutenção da ordem em sua família, condição esta frequentemente questionada pela jovem Lisa Simpson defensora do espírito dos anos de 1960.

O Sr. Burns, outro personagem masculino é colocado como um industrial capitalista inescrupuloso e mercenário. Patrocinador das "guerras biológicas" ele é hostilizado por várias jovens, principalmente as feministas, que lutam para fechar seu laboratório e suas fábricas. Para destruir o laboratório de germes, era necessária uma ação drástica. Utilizaram uma bomba de antibiótico e acabaram com os germes do Sr. Burns, que prometeu se vingar.

A vovó Simpson pacifista, a partir de então, foi identificada pela polícia e perseguida. Despediu-se de Homer e desapareceu, permanecendo refugiada por 
aproximadamente 27 anos, sendo enquadrada como terrorista e odiada pelo Sr. Burns, que acreditava que aqueles jovens haviam impedido os avanços das armas químicas para as guerras e o sucesso, ainda maior, de suas empresas. Burns, ao saber que a vovó Simpson estava viva, contacta o Federal Bureau of Investigation (FBI) e inicia uma perseguição à senhora Simpson. Após saírem da sala do empresário, os agentes de investigação do governo americano se questionam:

_ Como uma garota bonita se deixa levar por um monte de ideais tolos e promessas vazias?

_ Talvez achasse a guerra tão imoral, que justificasse.

_ Nossa, Joe. Você não é o mesmo desde que seu filho pirou no Vietnam.

_ Uma dor eterna.

Ao mudarem de cena de forma abrupta, os autores dOs Simpsons sugerem questionamentos acerca dos efeitos das "guerras imorais", muitas vezes, potencializadas pelo governo americano.

Levantar questionamentos históricos importantes é um dos principais diferenciais do desenho que, por meio de uma ironia politicamente incorreta, diferencia-se de outras séries. Expressando claramente a relação existente entre lucratividade, laboratórios de guerras biológicas e a luta dos jovens nos anos de 1960 contra tais empreendimentos, o desenho nos apresenta um componente fundamental que influencia seus criadores: o contexto do avanço do movimento jovem, a decadência da Guerra-fria e novidades tecnológicas dos meios de comunicação massivos. As problemáticas vividas pela família de Matt Groening, e mesmo por demais famílias de americanos a partir dos anos de 1960, criam um sentido de identificação que condiciona parte do sucesso do desenho que desde 1989, até 2010, continua sendo produzido e veiculado, em vários países do mundo. 


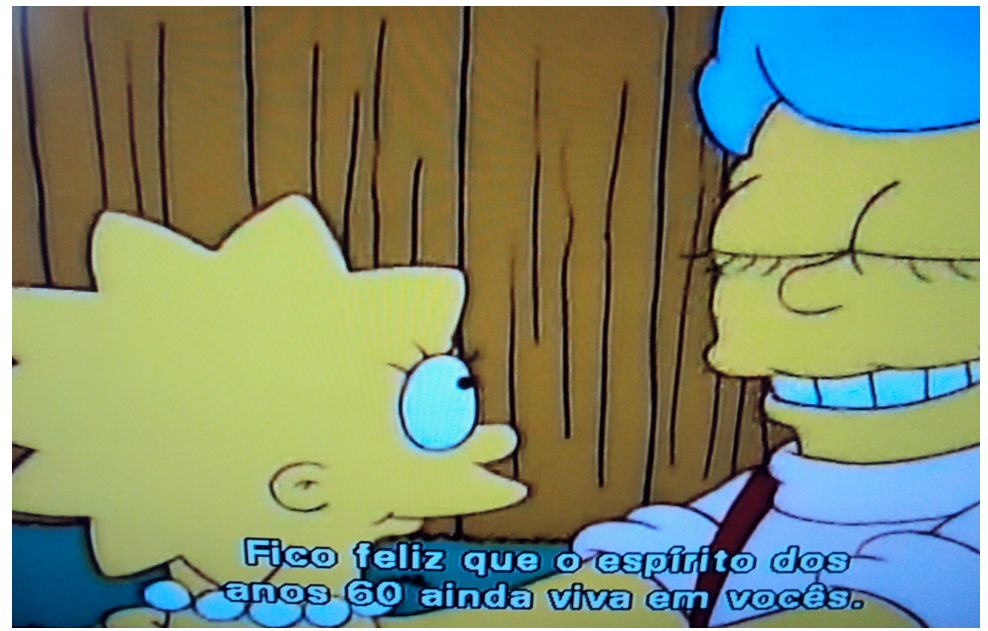

Figura 2: Lisa e a vovó Simpson: o espírito dos anos 1960

Fonte: Episódio “A vovó Simpson” (1995).

A frase "fico feliz que o espírito dos anos 60 ainda viva em vocês," revela o perfil da personagem Lisa, intelectual, ambientalista, pacifista e interessada em Jazz e Blues, como uma representante do feminismo dos anos de 1960. Sua procura por lutas em prol de causas humanitárias e a tentativa de melhorar o comportamento de seus familiares do sexo masculino, Homer e Bart Simpson, caracterizaram-na como uma personagem dinâmica e inteligente, porém, menos marcante do que seus familiares masculinos, na construção dos episódios que geralmente privilegiam estes últimos. A respeito de tal questão, destacamos a análise da personagem feita por Snow e Snow:

\section{LISA E SUA BONECA}

Um possível motivo é a suposta impopularidade de suas opiniões: alguns críticos rotulam Lisa como uma pequena e precoce feminista, baseando-se em sua rejeição a vida limitada de Marge e sua tendência para as campanhas e protestos, como a campanha para reformar toda a indústria de bonecas em 'Lisa versus Malibu Stacy', que aparece em quase todos 'os melhores episódios' da lista. Lisa desaprova as coisas tolas e chauvinistas que sua nova Malibu Stacy falante foi programada para dizer, e com seu jeitinho impetuoso vai diretamente ao encontro com o criador da boneca (SNOW, SNOW, 2004, p.131).

Ao discutir sobre "A política sexual em Os Simpsons", os autores frisam que o desenho procura questionar as devoções televisivas de "Papai sabe tudo" dos anos de 1950 e até a qualidade da programação da empresa que os patrocina, a FOX. Apesar disso, é mantida uma política sexual conservadora, pois, a cidade de Springfield tem população predominantemente masculina, a grande maioria dos episódios se concentra em Bart e Homer 
e a caracterização de Lisa (exposta acima) e Marge já marcavam outras séries televisivas americanas. Ao abordar sobre a personagem Marge, Snow afirma:

\begin{abstract}
À primeira vista. Marge é insurgente como mãe da televisão. Seu cabelo azul bem armado e sua pele amarela a tornam visualmente espantosa. Sob um exame mais cauteloso, porém, ela permanece dentro dos limites das mães de TV dos anos 1950 e início dos anos 1960. O cabelo bem feito faz lembrar as mães de Harriet Nelson e June Cleaver. Seu colar de perólas lembra Margaret Anderson (Papai Sabe Tudo), June Cleaver, Donna Stone (The Donna Reed Show), e até Wilma Flintstone. Na casa ou em público, Marge usa o convencional vestido de suas antecessoras dos anos de 1950 e 1960. O vestido da mãe de TV foi apenas brevemente subvertido por Mortícia Addams e Lily Munster entre 1964 e 1966. E como muitas de sua linhagem, a maternidade a tornou relativamente assexuada, embora sempre tradicionalmente feminina (SNOW, SNOW, 2004, p.128).
\end{abstract}

No trecho acima, evidencia-se o fato de que a personagem Marge Simpson é criada nos moldes de outras séries de sucesso nos Estados Unidos. Podemos acrescentar que isso também ocorre com os demais membros da família. É evidente que não queremos combater a ideia de que Os Simpsons é uma crítica aos problemas vividos por uma família de classe média americana, entretanto, a composição dos personagens e as próprias críticas não desfazem a família nuclear, ao contrário, ao fim de cada episódio, os vínculos familiares são revitalizados.

Além do episódio apresentado acima, Daniela Sacuchi Amereno, ao discutir sobre o descaminho do feminismo nos Simpsons; corrobora a idéia da hegemonia masculina na narrativa e na própria cidade de Springfield. Tendo como referência central o episódio "Nos somos jovens, jovens", exibido pela primeira vez nos Estados Unidos em 1991, ela destaca que, em um movimento de flashback, a família Simpson, diante de problemas técnicos com a televisão, resolve contar a história do encontro de Marge e Homer, retomando o passado. Marge rememora sua participação no movimento feminista, em 1974, na cidade de Springfield, em que chegou a queimar um sutiã, mas foi repreendida pelo diretor e levada para um castigo. Nesse ínterim, Homer e um amigo são encontrados fumando no corredor e também recebem castigo do diretor da escola. É, nesse momento, que o casal se encontra e inicia-se a posterior paixão. Homer procura enfrentar os debates políticos, mas sua inteligência limitada dificulta sua aproximação com Marge. No dia do baile da escola, Marge escolhe Artie Ziff (garoto intelectual) para acompanhá-la. Os dois recebem o prêmio de rei e 
rainha do baile e Homer fica desolado. Artie se oferece para acompanhar Marge até sua casa após a festa e ultrapassa os limites sexuais impostos por Marge. Assustada e decepcionada ela foge e encontra Homer.

Segundo Daniela Sacuchi Amereno, toda a narrativa é construída sobre o prisma do masculino e, a respeito do descaminho do feminismo no episódio, esclarece:

\footnotetext{
Diegeticamente, em 1974, enquanto Marge se preocupa com a causa feminista, é inteligente e dedicada, Homer fuma no banheiro escondido, não gosta de estudar e é alienado aos acontecimentos do mundo. Nos dias atuais, Marge é esposa dedicada e mãe boazinha que cuida da casa, ama, compreende e aceita a estupidez de seu homem, perdoando as maiores atrocidades, ao passo que Homer é egocêntrico, preguiçoso, mal educado e anula todos os esforços de Marge na criação dos filhos. Essa cultura patriarcal se sobrepondo aos ideais feministas pode sugerir que o episódio também é uma crítica ao caminho ou descaminho que o movimento feminista tomou. (AMARENO, 2006, p.58).
}

Assim, enquanto a dedicação de Marge à família, após o casamento com Homer, teria sido fator preponderante para por um fim ao seu engajamento pelas causas políticas e sociais, por outro lado, Homer tornou-se cada vez mais individualista e com frequentes desvios de caráter. Porém, contrariando um pouco o caminho de análise seguido pela autora, pensamos que os homens são apresentados, na maioria das vezes, como idiotas, enquanto preocupações e resoluções dos problemas familiares são temáticas que aparecem vinculadas à Marge e Lisa, personagens configuradas como inteligentes. Nesses termos o fato de os personagens masculinos figurarem como ignorantes e estúpidos e as femininas como inteligentes, revela, no mínimo, um paradoxo proposital.

No episódio "Lisa, uma Simpson”, a moça fica preocupada ao supor que poderia estar condenada geneticamente à idiotice mas, no final do episódio, sente um grande alívio ao saber que o gênero pode tê-la poupado. Paul Halpern destaca que Lisa ficou aflita, quando seu avô lhe explicou que existe uma predisposição genética para o declínio mental que se ativa na metade da infância. Para acalmar a filha, Homer convida vários parentes para darem seus depoimentos. Enquanto os homens deixam a garota ainda mais apavorada com seus relatos de fracasso, as mulheres apresentam experiências vividas que evidenciam carreiras de sucesso. As explicações da denominada doutora Simpson, esclarecendo Lisa que o gene defeituoso está alojado no cromossomo $\mathrm{Y}$ e é transmitido apenas de homem para homem a 
tranqüilizaram a moça, ou seja, ela estava salva da idiotice masculina. É importante esclarecer que o assunto continua sendo alimentado como polêmico e controvertido:

\begin{abstract}
A inteligência é um tema complexo; a vivacidade intelectual e o sucesso dependem de uma variedade de fatores, tanto ambientais quanto genéticos, muitos dos quais ainda não são completamente compreendidos. $\mathrm{Na}$ verdade, esta complexidade é apresentada em outros episódios da série, em que as diferenças entre mulheres e homens da família Simpson não são tão evidentes. Por exemplo, no episódio 'Irmão, Onde Estarás?', Homer se encontra com Herb, seu meio-irmão há muito desaparecido, que se revela rico e extremamente bem sucedido. Em 'Os Monólogos da Rainha', Homer viaja para a Inglaterra e encontra Abbie, sua meia-irmã também há muito desaparecida, que é espantosamente semelhante a ele na voz, no aspecto e na inteligência (HALPERN, 2008, p.25).
\end{abstract}

Essas variantes, acrescidas de outras, como a busca pela popularidade e lucro, típicas do final do século XX, talvez possam explicar a decisão atribuída à personagem Marge Simpson, em 2009, de posar para a revista Playboy, em um ensaio erótico. Observemos abaixo algumas imagens:
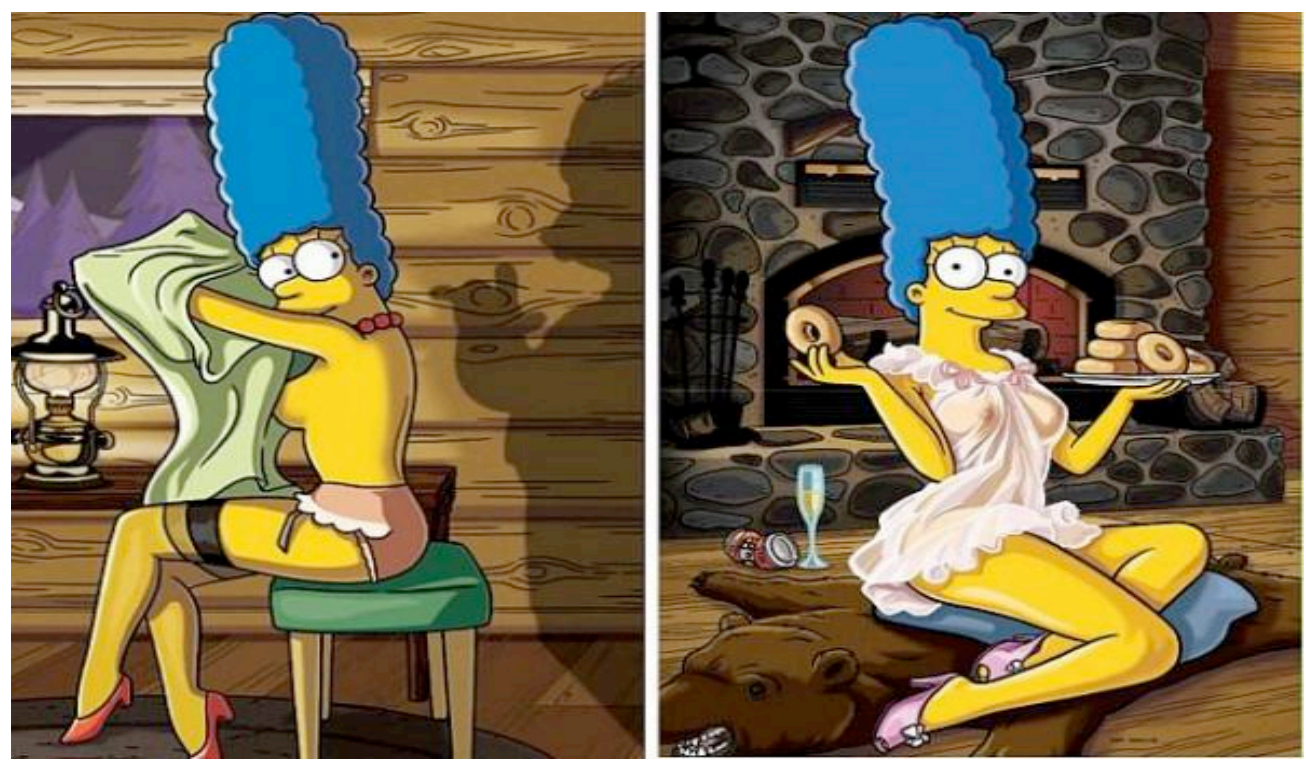

Fotografia 16: Marge Simpson nas páginas da Playboy (2009)

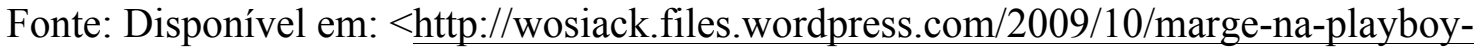
6201.jpg>. Acesso em: 10 de dez. 2010.

Em comemoração aos 20 anos da série, Marge Simpson faz seu primeiro ensaio sensual para a principal revista masculina americana. A proposição de liberdade sexual, no 
percorrer dos vinte anos de desenho, alterou, gradativamente, algumas posturas da personagem simpsoniana. Em outros episódios, Marge já havia beijado uma pessoa do mesmo sexo e, em novembro de 2009, a tradicional mamãe Simpson, empunhando as rosquinhas Donuts, muito desejadas por Homer, posou para a Playboy americana. É interessante perceber que, na imagem à esquerda do observador, a "presença de Homer" é novamente marcada, porém, em vez das rosquinhas, é possível visualizar sua sombra no costado de Marge. Liberdade sexual? Até que ponto essa decisão poderia ser atribuída à influência dos anos de $1960 ?$

Mesmo caracterizando-se como uma mãe de perfil conservador, na maioria dos episódios, Marge tem uma vantagem sobre suas colegas de outras séries televisivas: "mesmo depois de anos de casamento e já com três filhos, ela tem uma vida sexual satisfatória" (SNOW, SNOW, 2004, p.131).

Comumente, os roteiristas de televisão americanos costumavam construir suas personagens femininas, principalmente as mães, como pessoas que, ao optarem pelo casamento, abdicaram, direta ou indiretamente, do sexo e da sensualidade. Como capa da Revista Playboy, Marge Simpson quebra a norma televisiva, demonstrando que, apesar de exploradas menor número de vezes, as personagens femininas em Os Simpsons têm um papel fundamental para entendermos a composição do desenho.

\footnotetext{
Marge garante aos seus homens que os ama do jeito que eles são; Lisa os faz querer melhorar, e os orienta em direção dessa possibilidade. Esses papéis são magníficos e dramaticamente significativos, e parecem atribuir as melhores qualidades humanas à fêmea da espécie. Entretanto, ser uma inspiração para sujeitos estúpidos em todo lugar (ou na sua família) ainda não questiona a posição desses sujeitos bem no centro do palco da vida (SNOW, SNOW, 2004, p.138)
}

\section{Considerações finais}

Quatro gerações de mulheres protagonizam as relações familiares da família Simpson: Vovó Simpson, Margie, Lisa e Maggie. A última é apenas uma menina bebê, mas muito inteligente e independente. Margie e Lisa são claramente influenciadas pela Vovó Simpson e seu passado de feminista-ativista-pacifista e as premissas das mudanças propostas anos de 1960 expressas no movimento que generalizamos como contracultura.

$\mathrm{O}$ século XX é um referencial no que se refere às mudanças culturais, sociais e econômicas no mundo ocidental. Eric Hobsbawn o caracteriza como um século curto iniciado 
em 1914 com a Primeira Guerra Mundial e terminando em 1991 com a queda da União Soviética. Neste período, considerado pelo autor como breve, as transformações foram muito rápidas. Quanto à atuação das mulheres o autor afirma que ocorreu uma "amplitude da nova consciência de feminilidade." (HOBSBAWN, 1995, p. 306) ancorada na entrada em massa das mulheres no mercado de trabalho, assim como uma expansão na educação superior para as mulheres.

Segundo Margareth Rago, até aproximadamente o final dos anos 1960, a identificação feminina relacionava-se diretamente com a maternidade e a esfera privada do lar (RAGO, 2004, p. 31), mas nas décadas seguintes este quadro foi revertido significativamente e as mulheres passaram a se ocupar de outras questões, além das domésticas.

Foi na década de 1960, palco das experiências que vão marcar a vida da Vovó Simpson, que os Estados Unidos mostraram para o mundo todo seu poderio, político e militar, explícito na guerra do Vietnã e também seu modelo cultural principalmente por meio do cinema e da música. Parte da sociedade apoiava as ações pacíficas e não-pacíficas do governo norte-americano, pois a era intensa a propaganda com intuito de enaltecer o sentimento de patriotismo nacionalista. É neste contexto que surgem os primeiros indícios de uma contracultura nos Estados Unidos, segundo Paes

(...) para milhões de jovens naquela década, a saída vislumbrada foi a busca de um mundo alternativo. Da recusa da cultura dominante e da crítica ao establishment ou "sistema" (como então se dizia), nasceram novos significados: um novo modo de pensar, de encarar o mundo, de se relacionar com as outras pessoas. Da recusa surgia, na verdade, uma revolta cultural que contestou a cultura ocidental em seu âmago: a racionalidade. (PAES, 1997, p. 22)

Se na Tchecoslováquia, o clamor democrático gera o que passamos a conhecer como a Primavera de Praga, nos EUA protestos contra a guerra do Vietnã se intensificam e os conflitos raciais emergem em várias cidades do país.

Assim, na turbulência da década de 1960, surge a demanda por um modo de vida alternativo, designado de modo geral como movimento Hippie. Seus adeptos se voltaram para a natureza e para uma vida mais simples e para arranjos familiares e afetivos diferentes do modelo tradicional burguês. 
Nesse contexto, toma fôlego o movimento feminista que passou a defender com mais força o respeito à liberdade sexual, recusar os modelos tradicionais de casamento e a contestar a lógica da dominação masculina. Este anseio por liberdade e igualdade, para acabar com a repressão internalizada pelas mulheres tinha seu ícone na escritora francesa Simone de Beauvoir que influenciou milhões de mulheres e abriu caminho para o feminismo contemporâneo. A partir de então, as mulheres passaram a se contrapor ao modelo vigente, que podemos resumir como "rainhas do lar" (CALEIRO, GUSMÃO, 2012).

Conforme o exposto, embora de forma sucinta, podemos afirmar que as transformações sociais e culturais das décadas de 1960 e 1970 contribuíram para promover novas formas de atuação das mulheres na sociedade e na vida familiar.

Dessa forma podemos considerar que o processo de mudança sobre a vida das mulheres, está associado a um contexto histórico específico. Com o passar do tempo o discurso sobre a independência e a individualidade feminina foi cada vez mais se alastrando na sociedade (FERNANDES, CALEIRO, 2011, p.4).

Se o papel das mulheres na vida pública passou por transformações incontestáveis seus reflexos também foram sentidas na vida privada, ou seja, nas relações familiares. Não por acaso, como representantes destas mudanças, as mulheres da família Simpson também retratam as novas formas de organização familiar ocidental e contemporânea.

Sobre essas mudanças traduzidas na análise de seriados americanos que fizeram sucesso no Brasil na década de 1960, como "Papai sabe tudo", Leila M.T.de Brito lembra que o personagem central não mais representava o pai autoritário de décadas passadas, mas o chefe de família que "simbolizava o saber paterno, transmitido a partir de suas vivências. Ponderado, inteligente, sempre dispunha de palavras sábias ou de solução gloriosa para as situações criadas por seus filhos" (BRITO, 2005, p.48). O famoso seriado "Bonanza" representante típico dos seriados do Velho Oeste também apresentava a figura paterna como um homem portador de qualidades másculas, autoritário, justo e bom.

A análise destes seriados demonstra que os mesmos reproduziram "o consentimento sociocultural dado ao homem na época..." (BRITO, 2005, p.48) tanto na resolução de conflitos familiares quanto políticos. A família se organizava de forma hierárquica e o homem 
ocupava o lugar de destaque, não havia questionamentos quanto às desigualdades entre homens e mulheres.

Emblematicamente, na década de 1990 Os Simpsons, representantes de uma família de classe média norte-americana, a figura paterna é constantemente ironizada e não mais representa o homem sábio e justo, embora seu papel na trama familiar seja essencial. Para Sócrates Nolasco "Homer é uma referência importante para a série. É por seu intermédio que a inteligência de Lisa e o senso de justiça de Marge são potencializados e mais positivados" (NOLASCO, 2001, p.55.)

À assertiva de Nolasco acrescentamos a influência da Vovó Simpson, herdeira e propagadora das idéias feministas das décadas de 1960 e 70.

Entretanto, mesmo considerando que o feminismo, conforme a proposta atual, não aponta para a desqualificação da figura masculina, mas para a desmistificação das diferenças culturais entre homens e mulheres, deve-se considerar a assertiva de Sócrates Nolasco. Para o autor, as "crises de identidade" que marcaram o final do século XX também abriram espaço para "a positivação de identidades até então negativadas (mulher, etnia e homossexuais). E, se as crises positivaram as identidades até então não consideradas, por outro lado ser homem "passou a significar sinônimo de truculência, boçalidade ou daquele que é politicamente incorreto" (NOLASCO, 2001, p.14). Sem dúvida, assim é Homer Simpson.

A identificação dos personagens simpsonianos com o público é uma questão enfatizada, claramente, pelo principal agente de estudos da história, o tempo. Ao ser produzido anualmente e em série, além da longevidade, Os Simpsons povoam a televisão americana e brasileira há muitos anos. O formato da série animada, muito mais do que um filme, condiciona uma relação diferenciada com o público, pois, convivendo durante muito tempo diariamente, com as peripécias da família, o público pode, ou não, identificar-se, em alguns momentos, com os personagens; em outros momentos, de maneira inversa, os personagens podem se adequar às mudanças sociais condicionadas pelo público. $\mathrm{O}$ fato de Marge posar para a Playboy americana apresenta uma conduta comum, apreciada por inúmeras pessoas do grande público que cultuam as celebridades americanas. No Brasil não é diferente.

Nesse sentido, a proximidade do personagem com o humano, a relação das celebridades com os personagens, povoa um mundo construído pelo capital, pelas tecnologias e pela valorização das imagens e de comportamentos fazem parte da realidade social 
contemporânea. Mulheres fortes, que enfrentam suas crises de identidades e prezam sua liberdade representam dimensões do feminino que devem ser celebradas.

Destarte, há questões que devem ser repensadas quando a rigidez de um contexto não abre espaço para a alteridade. "O tom acusatório e depreciativo, comum de se encontrar nos diálogos contemporâneos sobre a presença dos homens no mundo, retratam bem este estado de coisas" (NOLASCO, 2001, p.16)

De acordo com Marc Ferro (2009), as imagens pertencem também àqueles que as vêem. Assim, o efeito de um filme, ou em nosso caso, do desenho, não depende apenas de uma análise daquele que produz e sim da maneira como pessoas ou comunidades vêem a produção, de como a percebem, de sua percepção. Nessa perspectiva, as questões postas pela família Simpsom passam a ser dependentes dos olhares dos indivíduos que se identificam com elas.

Não por acaso, Homer nos faz rir.

\section{Referências bibliográficas}

AMERENO, Daniela Sacuchi. O descaminho do feminismo nos Simpsons. Cenários da Comunicação, São Paulo, p. 49-63, 2006.

CALEIRO, Regina Célia Lima, GUSMÂO, João versiani Fagundes. História, corpo e feminismo. Histórica. Revista Eletrônica do Arquivo do estado de São Paulo. 2012

FERNANDES, Railde, CALEIRO, Regina Célia Lima Caleiro. Literatura para mulheres: discurso feminista e submissão feminina na contemporaneidade In: CAMPOS, A. P.; GIL, A. C. A.; SILVA, G. V. da; BENTIVOGLIO, J. C.; NADER, M. B. (Org.) Anais eletrônicos do III Congresso Internacional Ufes/Université Paris-Est/Universidade do Minho: territórios, poderes, identidades (Territoires, pouvoirs, identités). Vitória: GM Editora, 2011.

HALPERN,Paul. Os Simpsons e a ciência: eles podem nos ensinar sobre física, robótica, a vida e o universo. São Paulo: Novo Conceito Editora, 2008.

HOBSBAW, Eric Era dos Extremos: o breve século XX. São Paulo: Companhia das Letras, 1995.

NOLASCO, Sócrates. O apagão da masculinidade. Trabalho e Sociedade. Rio de Janeiro, n.2, 2001.

NOLASCO, Sócrates. De Tarzan a Homer Simpson. Rio de Janeiro, Rocco, 2001.

SNOW, Dale E.; SNOW, James J. Política sexual simpsoniana. In: Os Simpsons e a filosofia. São Paulo: Madras, 2004.

PAES, Maria Helena Simões. A década de 60. Rebeldia, contestação e repressão política. São Paulo: Atica, 2003.

RAGO, Margareth. Ser mulher no século XXI: ou carta de alforria. In: VENTURINI, Gustavo. et al. A mulher brasileira nos espaços público e privado. São Paulo: Editora Fundação Perseu Abramo, 2004. 
Original recebido em: 23/10/2012.

Aceito para publicação em: 23/11/2014.

Sobre os autores

Alessandro de Almeida

Doutor em História pela UFU

Professor do Instituto Federal do Norte de Minas

Regina Célia Lima Caleiro

Doutora em História pela UFMG

Professora da Universidade Estadual de Montes Claros 